\title{
Phylogenetic and ecological correlates with male adult life span of rainforest butterflies
}

\author{
Jan Beck
}

Received: 8 January 2007/ Accepted: 2 April 2007/Published online: 5 May 2007

(C) Springer Science+Business Media B.V. 2007

\begin{abstract}
Adult life spans are an important life history variable in butterflies, but have rarely been investigated in cross-species comparisons. Using 377 captive specimens from a Bornean rainforest assemblage (wild catches with low wing wear, belonging to 102 species) under standardized feeding conditions, substantial differences in the average adult life spans of species were observed, ranging from few days to almost three weeks. Analyses were carried out on the 30 most common species (247 specimens, only males). They revealed that related taxa had similar life spans, with nymphalids and some lycaenid groups being generally longer-lived than other taxa. Two traits of adult feeding behaviour are strong predictors of longevity in multivariate, phylogeny-controlled analyses: Fruitfeeding (versus nectar feeding) is associated with longer life spans, whereas the occurrence of mud-puddling behaviour is associated with short adult life. Larval feeding, male territoriality and a number of morphological measures showed no independent relationships with life spans. Furthermore, there was no evidence that long-lived species have larger geographic distributions (i.e., are better dispersers). Explanatory hypotheses are put forward, which may be a starting point for further investigations.
\end{abstract}

Keywords Borneo · Fruit-feeding · Lepidoptera · Life history · Longevity · Mud-puddling $\cdot$ Phylogenetic signal

Electronic supplementary material The online version of this article (doi:10.1007/s10682-007-9179-3) contains supplementary material, which is available to authorized users.

\section{J. Beck $(\bowtie)$}

Kuala Belalong Field Studies Centre, University of Brunei Darussalam, Tungku Link, Gadong 1410, Brunei

e-mail: jan.beck@unibas.ch

Present Address:

J. Beck

Department of Environmental Sciences, Institute of Biogeography, University of Basel, St. JohannsVorstadt 10, Basel 4056, Switzerland 


\section{Introduction}

Adult life stages of holometabole insects serve a number of purposes such as dispersal, migration, finding mates or laying eggs at suitable sites. Their duration is, therefore, a crucial life history dimension (see Carey 2001 for review). In butterflies, which have been particularly well-investigated (e.g. Nylin and Gotthard 1998; Boggs 1997; Jervis et al. 2005), life spans vary greatly between species. Previous research has mainly focussed on comparisons within species or between exemplars (e.g. Braby 2002; Karlson and Wiklund 2005), particularly regarding nutritional effects on aging or other fitness-related parameters (see below for references). There have not been many attempts to explain butterfly life span variation from species-specific traits in interspecific, comparative studies involving many species.

Previous data on adult life spans of butterflies stemmed from specimens held in captivity (e.g. Kelson 2002; Bauernfeind and Fischer 2005; Karlson and Wiklund 2005) or from mark-recapture studies (e.g. Nowicki et al. 2005; Molleman et al. in press). While most species appear to live only up to a few weeks, some tropical fruit-feeding taxa, as well as pollen-feeding Heliconius (Erhardt and Baker 1990; Boggs 1997), can live up to several months.

Life span, as an adaptive characteristic of a species, may be expected to be ultimately shaped by factors such as resource distribution, social system (e.g. Carey 2001; and references therein) and mortality risks (Stearns 1992; Bronikowski and Promislow 2005). However, due to niche conservatism (e.g. Wiens and Graham 2005) life spans may also be limited by physiological aging. Adult resource use (i.e. feeding habit), for example, can set physiological limits to achievable life spans (e.g. Erhardt and Baker 1990; Braby and Jones 1995; Boggs 1997; Beck in press; and references therein). Mortality factors such as predation are less predictable, but they can also be affected by behavioural and physiological adaptations (e.g. habitat choice, predator avoidance).

In this study data on adult longevities in captivity are reported for a number of butterfly species from a tropical rainforest assemblage in Borneo. These data were tested for a phylogenetic signal (i.e. whether related taxa have similar life spans). Furthermore, the following hypothetical relationships with a number of species traits were tested (relating to larval and adult feeding, morphology and mating system), which might serve as causal explanations of life span variability.

(1) Taxa with similar larval diet have similar life spans. Feeding on low-quality larval host plant species, for example, may leave more need for 'compensatory' adult feeding to attain resources necessary for reproduction (cf. Mevi-Schütz and Erhardt 2005); such species may hence evolve longer adult life spans.

(2) Species with an adult diet of rotten fruits live longer than flower visitors. Previous data indicate that the mainly tropical guild of fruit-feeding species (cf. Molleman et al. 2005a) can attain considerably higher ages than nectar feeders (the majority of butterfly taxa).

(3) The presence or absence of mud-puddling behaviour relates to longevity. However, predictions on the direction of this relationship are equivocal. High predation risk during mud-puddling has been suggested (Molleman et al. 2005b), which should lead to fast reproduction and low investment in adult longevity. Puddling may, on the other hand, serve the intake of amino acids in some tropical species (Beck et al. 1999), allowing prolonged adult life. Mud-puddling is probably a sexually selected trait, with collected substances serving as nuptial gifts in many species. The amount 
or quality of sampled substances might relate to available sampling time, hence life span. Such circumstances might also serve the evolution of prolonged adult life.

(4) Large body size, hence higher 'robustness' to environmental variation is associated with longer life spans.

(5) Species with wide thoraxes, and/or higher 'wing load', live longer than other taxa. Morphologies related to high flight-speed and agility (Dudley and Srygley 1994) may allow more successful predator escape, hence lower mortality, and should consequently lead to higher investment in preventing physiological aging.

(6) Territorial males live longer than males of non-territorial species. Long-lived males in territorial species might have more chances to mate, particularly if mating opportunities are rare and unpredictable (Gotthard et al. 2000; Beck and Wagner 2006 for a species included here). This fitness-enhancement could drive the evolution of longevity.

(7) Lastly (with reversed causality of the relationship), long-distance dispersal ability is positively related to long life spans. Adult life spans have been suggested to affect dispersal abilities in flying insects, particularly over long-distances (de Boer and Duffels 1996; Beck and Kitching 2007; and references therein). Very short-lived taxa may be unlikely to be good dispersers.

\section{Methods}

Study site and field methods

The study was carried out at the Kuala Belalong Field Study Centre (KBFSC; Brunei, northern Borneo; $4^{\circ} 33^{\prime} \mathrm{N}, 115^{\circ} 09^{\prime} \mathrm{E}$, ca. $50 \mathrm{~m}$ a.s.l.), surrounded by steep hills covered in virgin lowland rainforest (Cranbrook and Edwards 1994). Climatic patterns around KBFSC are tropical with very high humidity (ca. $90 \%$ daytime, $>99 \%$ at night, very little seasonal variation; see Dykes 2000 for data). Rainfall is high (typically 4000-5000 mm per year) and varies with acyclic ENSO events as well as a (weak) seasonal pattern, but year-to-year variation of the latter is high. Temperatures usually range between $22^{\circ} \mathrm{C}$ at night and $33^{\circ} \mathrm{C}$ during the day. Mean monthly temperatures appear inversely associated with rainfall patterns, but variation is very low (range $1.7^{\circ}$ ). For the study period only daily precipitation measures are available. Monthly precipitation ranged between $167 \mathrm{~mm}$ (July 2006) and $>750 \mathrm{~mm}$ (April 2006). Diversity patterns and phenology of the highly diverse butterfly assemblage at KBFSC have been studied by Orr and Haeuser (1996), who reported 324 species, or $34 \%$ of the described species richness of Borneo, within ca. one $\mathrm{km}^{2}$ of forest around the field centre.

Adult specimens were caught with a butterfly net at KBFSC and surrounding forest between June 2005 and August 2006. All species within reach were sampled except for many of the blue-winged polyommatine Lycaenidae, as well as some members of the nymphalid genus Tanaecia, as species identification in these groups (especially in living or old specimens) is exceedingly difficult.

Specimens were carefully packed in glossy paper and transported in a plastic box to the field centre. They were kept individually (without mating opportunity) in cages varying in size from $20 \times 20 \times 30 \mathrm{~cm}$ to $2 \times 2 \times 2 \mathrm{~m}$, depending on the size and flight activity of species. Round cages prevented wing damage due to panicking flight behaviour that was occasionally observed in captive specimens. Terrariums were placed under a roof on a 
shady veranda, hence under near natural climate conditions. Only specimens without any sign of wing wear (an indicator of age; e.g. Kemp 2001) were used to reduce effects due to pre-capture age differences between specimens. Furthermore, data of specimens that died within $24 \mathrm{~h}$ after catch were excluded from analyses if there was any suspicion that they might have been injured during catch or transport. Cages were inspected daily for dead specimens, whereas feeding solutions (see below) were replaced every 4-5 days; the extremely high humidity at the site prevented significant evaporation of feeding fluids. After death of specimens, cages were cleaned with soap to reduce chances of disease transmission.

Food solutions were placed in Petri dishes with a piece of coloured paper tissue as a visual cue (feeding was observed in all species). Butterflies had access to water, sodium solution ( $0.1 \mathrm{~mol} / \mathrm{l} \mathrm{NaCl}$; cf. Molleman et al. 2005b), sucrose solution (commercially available, white cane sugar, 25\%; this type of sugar and concentration is found in many flower nectars and has been used before in similar studies), and amino acids (mix of 16 essential amino acids in sugar water, in total $1.6 \mathrm{~g}$ per $100 \mathrm{ml}$; see Beck in press for details).

Preliminary identification after capture was verified after death, following pinning, using literature by Otsuka (1988), Seki et al. (1991), Maruyama (1991) and Corbet and Pendlebury (1992; specimens are deposited at KBFSC).

\section{Methods of analysis}

A phylogeny of species was manually reconstructed from recent molecular higher-taxon phylogenies (Wahlberg et al. 2005; Peña et al. 2006; Braby et al. 2005, 2006). For species not sampled in these trees it was assumed their position within current generic classifications were correct in an unresolved polytomy with tested taxa (Corbet and Pendlebury 1992). The test for serial independence (TFSI, 10,000 randomizations, no branch lengths required; Abouheif 1999; software by Reeve and Abouheif 2003) was used to detect an impact of phylogeny on life spans.

Species were classified according to behavioural and dietary traits (male territoriality, fruit-feeding, mud-puddling) based on own observations (incl. proboscis microscopy) and information given in Corbet and Pendlebury (1992). Larval host plant data were taken from Robinson et al. (2001) and recent updates (G. Robinson, pers. comm.). Larval dietary niche breadth was measured as the number of utilized plant families (following APG 2003). As the number of host plant records differed strongly between species, rarefied numbers of plant families (for a common sample size of five records; see e.g. Simberloff 1978) were calculated to account for biases due to unequal sampling. Conclusions based on raw numbers of plant families (log-transformed, only species with $\geq 5$ records; data not shown) did not qualitatively differ from results presented here. The similarity of species' host plant choice was analysed by calculating a similarity index that accounts for differences in sample size and completeness, i.e. number of records (CNESS, based on utilized plant families; Trueblood et al. 1994). Similarity data were subjected to ordination (multidimensional scaling, MDS: 3 dimensions, Stress < 0.2; see Beck et al. 2006 for details on analogous analyses). Forewing lengths (FWL) and thorax widths were measured with a calliper (means of at least five specimens per species). Wing loads were calculated as Thorax/FWL. Distribution information was based on data given in Otsuka (1988), Seki et al. (1991), Maruyama (1991) and Corbet and Pendlebury (1992). Species where classified as (a) Borneo-endemics, (b) species occurring on islands of the Sundashelf (and the 
Asian mainland), and (c) species that are spread over Wallace's line (which required extensive crossing of water straits even at lowered sea levels during the Pleistocene). Various combinations of other classifications had been tried in preliminary analyses (not shown) to find meaningful patterns.

Data were checked for normality and log-transformed where necessary for the application of parametric test statistics. Besides standard methods, multivariate tests based on generalized linear models (GLMs; StatSoft 2001) were applied. To account for confounding phylogenetic effects in interspecific comparisons, information on species' relatedness was included into models using a variation of the eigenvector method (DinizFilho et al. 1998), whereby an ordination of a phylogenetic distance matrix represents variation in relatedness on a few axes. Instead of phylogenetic distances, which were not available, distances were measured in units of taxonomic classification (see references above), i.e. family, subfamily, tribe, sub-tribe, monophyletic group of genera, and genus. Multidimensional scaling (MDS), rather than principal component analysis, was applied to ordinate these data. Two dimensions reflect data structure well (Stress $<0.09$ ) and were included as predictor variables into models.

As in most species-rich, tropical species communities, many species were very rare. To buffer results against biased data based on single or few specimens, results are presented only for species where life span means of at least five specimens were available (assuming that means, but not maxima, are stable to sample size differences).

\section{Results}

Longevity data for 377 specimens belonging to 102 species were obtained. Only $6 \%$ of these data stemmed from females. As life spans in females of some species might differ from males (see Discussion), they were excluded from all analyses. For 30 species data for more than five male individuals (up to 19) were available to calculate species means (247 specimens; see Appendix S1 for data).

Life spans differed significantly between 30 species (ANOVA, log-transformed life spans: $\left.N=247, F_{1,29}=11.6, p<0.0001\right)$. The TFSI indicated a significant impact of phylogeny on life span data $(p=0.006)$. On family-level, nymphalids and some lycaenid groups were mostly long-lived, whereas papilionids, pierids, most skippers and the polyommatine Lycaenidae were rather short-lived (Appendix S2).

Life spans were tested for relationships with species traits (Table 1, Fig. 1). Effects of adult feeding-related parameters were strong and remained significant in phylogenetically controlled analyses. Life spans of mud-puddling taxa were significantly shorter than taxa not engaged in this behaviour. Fruit-feeding taxa lived significantly longer than nectar feeders. Effects of morphological measures were less clear. Taxa with wide thoraces lived significantly longer, whereas a positive relationship recovered between wing load and life span is perhaps spurious due to phylogenetic non-independence of data. A positive effect of FLW on life spans, on the other hand, became only evident after controlling for phylogeny. There were no significant relationships between longevity and male territoriality, larval diet-breadth or -similarity.

Some predictor variables were correlated to phylogeny as well as to each other (Appendix S3). For example, territoriality was typically associated with short forewings, high wing load, and a low incidence of mud-puddling, whereas fruit-feeders often had large thoraces. To account for independent effects on life spans, a multivariate model was 
Table 1 Effects of various independent variables on (log-transformed) mean life spans of $N$ species

\begin{tabular}{|c|c|c|c|c|c|}
\hline \multirow[t]{2}{*}{ Independent variable } & \multirow[t]{2}{*}{$N$} & \multicolumn{2}{|l|}{ Univariate } & \multicolumn{2}{|c|}{ Phylogeny-controlled } \\
\hline & & Test & $p$ & Test & $p$ \\
\hline Mud-puddling & 30 & $F_{1,28}=59.6$ & $<0.0001$ & $F_{1,26}=25.8$ & $<0.0001$ \\
\hline Fruit-feeding & 30 & $F_{1,28}=20.1$ & $<0.001$ & $F_{1,26}=14.5^{\mathrm{PHY}}$ & $<0.0001$ \\
\hline Territoriality & 30 & $F_{1,28}=2.0$ & 0.167 & $F_{1,26}=0.16^{\mathrm{PHY}}$ & $>0.20$ \\
\hline FWL & 30 & $t_{28}=1.2$ & $>0.20$ & $t_{26}=2.5^{\text {PHY }}$ & $\mathbf{0 . 0 2}$ \\
\hline Thorax & 30 & $t_{28}=2.5$ & 0.017 & $t_{26}=2.9^{\mathrm{PHY}}$ & $<0.01$ \\
\hline Wing load & 30 & $t_{28}=3.0$ & $<0.01$ & $t_{26}=1.1^{\mathrm{PHY}}$ & $>0.20$ \\
\hline Host plant families (rarefied) & 11 & $t_{9}=2.2$ & 0.052 & $t_{7}=1.52$ & 0.171 \\
\hline Host plant similarity (3 dim.) & 11 & $\left|t_{7}\right|<1.2$ & $>0.20$ & $\left|t_{5}\right|<0.7$ & $>0.20$ \\
\hline Distribution & 29 & $F_{2,26}=0.9$ & $>0.20$ & $F_{2,24}=2.6^{\mathrm{PHY}}$ & 0.09 \\
\hline
\end{tabular}

Generalized linear models (GLM) or multiple regressions (depending on data structure) were used to model univariate as well as phylogenetically controlled relationships (see main text for methods). Only test results for the respective independent variables are reported, whereas significant contributions $(p<0.05)$ of one or both phylogeny-dimensions are indicated by PHY. Significant effects are printed in bold
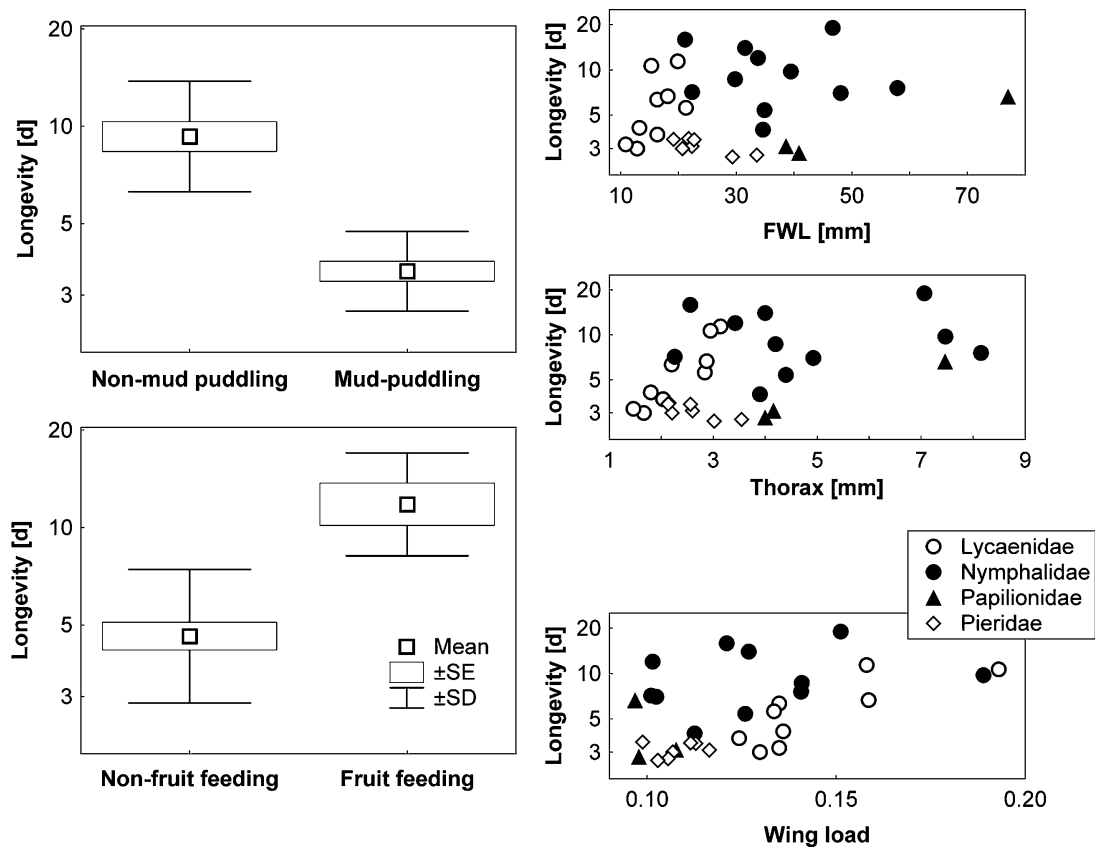

Fig. 1 Differences in the longevity (log-scale) of 30 species differing in adult feeding behaviour (left) and morphology (right). See Table 1 for statistical significance of relationships in univariate and phylogenetically controlled tests

used to test for significant relationships. Explaining life spans as GLM response variable was constrained by the relatively small sample size of 30 species, which did not allow including all predictor variables (to avoid model over-fitting). Here results for a simplified 
Table 2 Results of a Generalized Linear Model (StatSoft 2001; no interactions allowed) predicting (logtransformed) mean longevity from four species traits and two MDS-dimensions that represent phylogenetic relatedness of taxa (see main text for methods)

\begin{tabular}{lrr}
\hline Parameter & $\boldsymbol{F}_{1,23}$ & \multicolumn{1}{c}{$\boldsymbol{P}$} \\
\hline Mud-puddling & $\mathbf{1 7 . 9}$ & $<\mathbf{0 . 0 0 1}$ \\
Fruit-feeding & $\mathbf{4 . 5}$ & $\mathbf{0 . 0 4 4}$ \\
FWL & 2.8 & 0.105 \\
Thorax & 1.4 & 0.254 \\
Phylogeny-Dim1 & 3.2 & 0.087 \\
Phylogeny-Dim2 & 0.0 & 0.907 \\
\hline
\end{tabular}

The model is significant and predicts a high fraction of life span variability $\left(N=30, R^{2}=0.74, F_{6,23}=15.0\right.$, $p<0.0001$; significant predictors in bold print)

model are presented, which contained only those biological predictors that were shown to be significant in phylogeny-controlled, but otherwise 'univariate' analyses (Table 1). The two MDS-dimensions representing information on phylogenetic relatedness were also included as predictor variables into the model. Results (Table 2) showed that only the two adult feeding-related parameters (fruit-feeding, mud-puddling) are significantly related to life spans independently of other influences (including phylogeny).

In additional exploratory analyses, extended models were used to confirm that the simplified model did not ignore any other important effects. Strong effects of mudpuddling and fruit-feeding were found among all these models (not shown in detail). However, an extended model using all predictor variables except those related to larval feeding (data were available only for few species) indicated additional significances for FWL, thorax width and (marginally) wing load. There was no indication of a relationship with male territoriality in any model.

There were no significant differences in life-spans between distribution-classes in a univariate comparison, whereas data from phylogeny-controlled analyses only indicated a non-significant trend (Table 1). Shortest life-spans were found among Borneo-endemics, longest among species of the Sunda Shelf and the Asian mainland.

\section{Discussion}

Data presented above may suffer from a number of caveats that must be pointed out. Firstly, post-capture life span is not the same as total life span. Restriction to fresh-looking specimens might reduce this error, but the acquisition of wing damage also depends on movement patterns and wing strength, and thus might differ between species. Secondly, life span data derived from specimens in captivity may always be biased, positively or negatively, by keeping conditions. Temperature, for example, is a crucial factor in observed life-spans of temperate species (e.g. Karlson and Wiklund 2005), but probably plays only a minor role in the tropical outdoor setup used here (see above). Similarly, nonnatural larval host plants do not have to be considered here. Oviposition and mating (both excluded in the design used here), on the other side, may have effects on butterfly longevity in both sexes (e.g. Kaitala and Wiklund 1994; Fischer et al. 2004). Also, adult food quality and the prevalence of disease might differ between caged and free-roaming specimens. It is impossible to reliably asses whether keeping conditions generally shortened or prolonged 
life spans. The few available data on natural life-spans (mark-recapture studies of Bornean species: Beck and Schulze 2000; Tangah et al. 2006; Beck and Wagner 2006) are generally in agreement with captive specimen data presented above. Thirdly, data were collected over a period longer than a year. Environmental variation might have affected the mortality of specimens (despite low seasonality in the region, see above), invalidating comparisons between species not sampled at the same time. Graphic displays of data and a GLM analysis of such effects, using species identity, time-of-catch of specimens and precipitation as co-variables, are presented in Appendix S4. Results confirm life span differences between species, but also indicate a significant reduction of life spans with progress of the study, whereas there was no significant, independent effect of monthly precipitation. Least square means of (log)life spans from the GLM (at covariate means) were used to re-calculate analyses presented above with 'time-corrected' longevity data, which corroborated all results presented above (see Appendix S4 for details).

\section{Evolutionary interpretations}

In the following some interpretations with the aim of explaining findings in the light of life history evolution are proposed. These ideas might be working hypotheses to be tested in future work, but their tentative character must be stressed.

(1) Negative effects were recovered between mud-puddling behaviour and life span. Mud-puddling is possibly a very risky behaviour due to high predation risks (see also Burger and Gochfeld 2001; Molleman et al. 2005b). Butterflies engaged in this behaviour sit on the ground, usually against a plain background where their camouflage patterns are ineffective. They are relatively easy to spot and catch for a human, and the same might be true for natural predators such as birds. If mortality during mud-puddling was substantial, high investment into longevity would be futile. This might eventually lead to the observed short life-spans in mud-puddlers. Based on this hypothesis, it would be expected that predation rates in mud-puddlers are higher than in other species (though no data are available to assess this). It is also likely that sexual dimorphism in life spans would be found, as mud-puddling is usually only observed in males. The latter prediction could not, unfortunately, be investigated here, as females of the common mud-puddling species in the studied assemblage (e.g. Eurema, Troides) usually fly in the forest canopy where they cannot easily be caught. Pharmacophagous Danainae (Schneider 1993; and references therein) might be 'the exception that confirms the rule'-despite similarly risky behaviour, i.e. slow, predictable flight around smelly substances (including, for example, spilled petrol and paint in Euploea) they can attain relatively long life spans. Most Danainae species have aposematic colouration and therefore experience substantially lower predation threats. On a similar line of thought, it would be expected that species with a high wing load and hence better manoeuvrability and predator avoidance ability would experience lower mortality rates. Increased longevity could be selectively advantageous for these species. However, corroborating univariate patterns appear to be influenced by phylogeny and other parameters (e.g. many fruit-feeders have a stocky body shape).

(2) Evidence presented above showed a positive relationship between fruit-feeding and life span. Fruits might be a rich adult feeding resource. They might contain higher concentrations of nutrients than flower nectar (e.g. amino acids; Wendeln et al. 2000; Molleman et al. 2005c). Or, alternatively, their large size provides an overall larger quantity of nutrients than nectar despite equal or lower concentrations of nutrients. Adult amino acid feeding appears as a necessity for long life-spans in butterflies (e.g. Boggs 
1997; Beck in press), which may have evolved more easily in species (or clades) already adapted to feed on a rich resource. Molleman et al. (in press) recently reported exceedingly long life spans in African fruit feeding species. Expectations based on this idea are (a) that fruits usually taken by butterflies are indeed richer in relevant nutrients than nectar, (b) that very long life spans in non-fruit-feeding species are found only in taxa with another high-quality food source (as corroborated e.g. by pollen-feeding species; Boggs 1997), and (c) that among fruit-feeders there is still variation in life spans that can be explained by factors such as, e.g., mortality risks, resources availability or mating system.

Data did not support any other hypotheses. In particular, neither male territoriality nor morphological measures provided significant explanations for life span variability after accounting for effects of phylogeny and of the other variables. Furthermore, there was no evidence that life spans affect long-distance dispersal abilities (across water-straits). However, sample size (i.e. numbers of species) was low even with an 'entry criterion' of only five specimens, so low power of analyses might have hidden weaker effects. Furthermore, selection of species was not random, but dictated by ecological traits that may themselves relate to some of the analyzed variables (i.e. abundant species flying within reach for netting).

Results presented here refer exclusively to males, contrary to previous studies on butterfly longevity, which mostly treated effects on females (see above for references). Complex evolutionary interactions between resource availability, mating system (e.g. polyandry), costs and benefits of mating (e.g. due to nutrient transfer, Mevi-Schütz and Erhardt 2004), and sexually selected behaviour (e.g. in the context of this study, male territoriality and mud-puddling) may lead to differences in male and female life spans in some species (or even between populations within the same species; Gotthard et al. 2000; Wiklund et al. 2003). However, such effects will have to be studied in detail in interspecific analyses (with data for both sexes) before any general assessments on sex-specific longevities can be made.

\section{Conclusions}

Using captive specimens under standardized feeding conditions, substantial differences in the average adult life spans of a tropical rainforest butterfly assemblage were found, ranging from few days to almost 3 weeks. These differences are not randomly assorted with regards to the phylogeny of species (i.e. related taxa have similar life spans). Two traits related to adult feeding, fruit-feeding (vs. nectar drinking) and the occurrence of mud-puddling, are strong predictors of longevity (independently of the phylogenetic signal in data). Hypothetically, (a) mud-puddling species live shorter because this behaviour leads to high adult mortality due to predation, which selects against investment in long life; and (b) fruit-feeders live longer because they exploit a richer food source (e.g. with regards to amino acids) that permitted the evolution of longevity more easily. These hypotheses may be a starting point for further investigations in the system.

Acknowledgements I thank the staff of KBFSC, as well as J.-P. Lessard, A. Keller, K. Wagner and Dyg. Siti Nortasha for help with routine lab work. Furthermore, I am grateful to N. Blüthgen for supplying amino acids, K. Fiedler for advice on butterfly keeping, G. Robinson for sharing the latest version of his hostplant database, and U. Grafe for helpful discussions. Two anonymous reviewers provided very useful criticisms on earlier drafts of the manuscript, Simon P. Loader helped with the presentation. The study was financed by a Research Fellowship of the University of Brunei Darussalam. 


\section{References}

Abouheif E (1999) A method for testing the assumption of phylogenetic independence in comparative data. Evol Ecol Res 1:895-909

APG (Angiosperm Phylogeny Group) (2003) An update of the Angiosperm Phylogeny Group classification for the orders and families of flowering plants: APG II. Bot J Linn Soc 141:399-436

Bauernfeind SS, Fischer K (2005) Effects of adult-derived carbohydrates, amino acids and micronutrients on female reproduction in a fruit-feeding butterfly. J Ins Physiol 51:545-554

Beck J (2007) The importance of amino acids in the adult diet of male tropical rainforest butterflies. Oecologia 151:741-747

Beck J, Kitching IJ (2007) Correlates of range size and dispersal ability: a comparative analysis of sphingid moths from the Indo-Australian tropics. Glob Ecol Biogeogr 16:341-349

Beck J, Kitching IJ, Linsenmair KE (2006) Diet breadth and host plant relationships of Southeast-Asian sphingid caterpillars. Ecotropica 12:1-13

Beck J, Mühlenberg E, Fiedler K (1999) Mud-puddling behaviour in tropical butterflies: in search of protein or minerals? Oecologia 119:140-148

Beck J, Schulze CH (2000) Diversity of fruit-feeding butterflies (Nymphalidae) along a gradient of tropical rainforest succession in Borneo with some remarks on the problem of 'pseudoreplicates'. Transact lepidopt Soc Japan 51:89-98

Beck J, Wagner K (2006) Observations on the territoriality of male Arhopala aurea, a lycaenid butterfly of the rainforest understorey. Sepilok Bull 5:17-25

Boggs CL (1997) Reproductive allocation from reserves and income in butterfly species with differing adult diets. Ecology 78:181-191

Braby MF (2002) Life history strategies and habitat templets of tropical butterflies in north-eastern Australia. Evol Ecol 16:399-413

Braby MF, Jones RE (1995) Reproductive patterns and resource allocation in tropical butterflies: Influence of adult diet and seasonal phenotype on fecundity, longevity and egg size. Oikos 72:189-204

Braby MF, Trueman JWH, Eastwood R (2005) Where and when did troidine butterflies (Lepidoptera: Papilionidae) evolve? Phylogenetic and biogeographic evidence suggests an origin in remnant Gondwana in the late Cretaceous. Invertebrate Syst 19:113-143

Braby MF, Vila R, Pierce NE (2006) Molecular phylogeny and systematics of the Pieridae (Lepiodoptera: Papilionoidea): higher classification and biogeography. Zool J Linn Soc 147:239-275

Bronikowski AM, Promislow DEL (2005) Testing evolutionary theories of aging in wild populations. Trends Ecol Evol 20:271-273

Burger J, Gochfeld M (2001) Smooth-billed ani (Crotophaga ani) predation on butterflies in Mato Grosso, Brazil: risk decreases with increased group size. Behav Ecol Sociobiol 49:482-492

Carey JR (2001) Insect biodemography. Annu Rev Entomol 46:79-110

Corbet AS, Pendlebury HM (1992) The butterflies of the Malay peninsula. (4th edn, revised by JN Eliot). Malayan Nat Soc, Kuala Lumpur

Cranbrook E, Edwards DS (1994) A tropical rainforest- the nature of biodiversity in Borneo at Belalong, Brunei. The Royal Geographic Society, London \& Sun Tree Publishing, Singapore

de Boer AF, Duffels JP (1996) Historical biogeography of the cicadas of Wallacea, New Guinea and the West Pacific: a geotectonic explanation. Palaeogeography, Palaeoclimatology, Palaeoecology 124:153-177

Diniz-Filho JAF, de Sant'Ana CER, Bini LM (1998) An eigenvector method for estimating phylogenetic inertia. Evolution 52:1247-1262

Dudley R, Srygley RB (1994) Flight physiology of Neotropical butterflies: allometry of airspeeds during natural free flight. J Exp Biol 191:125-139

Dykes AP (2000) Climatic pattern in a tropical rainforest in Brunei. The Geogr J 166:63-80

Erhardt A, Baker I (1990) Pollen amino acids—an additional diet for a nectar feeding butterfly? Plant Syst Evol 169:111-121

Fischer K, O’Brien DM, Boggs CL (2004) Allocation of larval and adult resources to reproduction in a fruitfeeding butterfly. Funct Ecol 18:656-663

Gotthard K, Nylin S, Wiklund C (2000) Mating opportunity and the evolution of sex-specific mortality rates in a butterfly. Oecologia 122:36-43

Jervis M, Boggs CL, Ferns PN (2005) Egg maturation strategy and its associated trade-offs: a synthesis focusing on Lepidoptera. Ecol Entomol 30:359-375

Kaitala A, Wiklund C (1994) Polyandrous female butterflies forage for matings. Behav Ecol Sociobiol 35:385-388 
Karlson B, Wiklund C (2005) Butterfly life history and temperature adaptations; dry open habitats select for increased fecundity and longevity. J Anim Ecol 74:99-104

Kelson R (2002) Longevity of tropical butterflies in a butterfly house in California. Invertebrates in Captivity (Conference Proceedings). Sonoran Arthorpod Studies Institute, Arizona (USA), pp 169-177

Kemp DJ (2001) Age-related site fidelity in the territorial butterfly Hypolimnas bolina (L.) (Lepidoptera: Nymphalidae). Austr J Entomol 40:65-68

Maruyama K (1991) Butterflies of Borneo, vol. 2, no. 2: Hesperiidae. Tobishima Corp, Tokyo

Mevi-Schütz J, Erhardt A (2004) Mating frequency influences nectar amino acid preference of Pieris napi. Proc R Soc B 271:153-158

Mevi-Schütz J, Erhardt A (2005) Amino acids in nectar enhance butterfly fecundity: a long-awaited link. Am Nat 165:411-419

Molleman F, Grunsve RHA, Liefting M, Zwaan BJ, Brakefield PM (2005b) Is male puddling behaviour of tropical butterflies targeted at sodium for nuptial gifts or activity? Biol J Linn Soc 86:345-361

Molleman F, Krenn HW, van Alphen M, Brakefield PM, DeVries P, Zwaan BJ (2005a) Food intake of fruitfeeding butterflies: evidence for adaptive variation in proboscis morphology. Biol J Linn Soc 86:333343

Molleman F, van Alphen ME, Brakefield PM, Zwaan BJ (2005c) Preferences and food quality of fruitfeeding butterflies in Kibale Forest, Uganda. Biotropica 37:657-663

Molleman F, Zwaan BJ, Brakefield PM, Carey JR (2007) Extraordinary long life spans in fruit-feeding butterflies can provide window on evolution of life span and aging. Experimental Gerontology (in press; doi:10.1016/j.exger.2007.01.008)

Nowicki P, Richter A, Glinka U, Holzschuh A, Toelke U, Henle K, Woyciechowski M, Settele J (2005) Less input same output: simplified approach for population size assessment in Lepidoptera. Popul Ecol 47:203-212

Nylin S, Gotthard K (1998) Plasticity in life history traits. Annu Rev Entomol 43:63-83

Orr AG, Haeuser CL (1996) Temporal and spatial patterns of butterfly diversity in a lowland tropical rainforest. In: Edwards DS, Booth WE, Choy SC (eds) Tropical rainforest research—current issues. Kluwer, Drodrecht, pp 125-138

Otsuka K (1988) Butterflies of Borneo, vol 1. Tobishima Corp, Tokyo

Peña C, Wahlberg N, Weingartner E, Kodandaramaiah U, Nylin S, Freitas AVL, Brower AVZ (2006) Higher level phylogeny of Satyrinae butterflies (Lepidoptera: Nymphalidae) based on DNA sequence data. Molecul Phylogen Evol 40:29-49

Reeve J, Abouheif E (2003) Phylogenetic Independence, v 2.0. Dept Biol, McGill University (distributed freely by the authors on request)

Robinson GS, Ackery PR, Kitching IJ, Beccaloni GW, Hernández LM (2001) Hostplants of the moth and butterfly caterpillars of the Oriental Region. Nat Hist Mus (Lond) \& Southdene Sdn Bhd, Kuala Lumpur

Schneider D (1993) Danaine butterflies: a didactic story about chemical ecology. In: Malcolm SB, Zalucki MP (eds) Biology and conservation of the monarch butterfly. Nat Hist Mus, Los Angeles, pp 19-28

Seki Y, Takanmi Y, Otsuka K (1991) Butterflies of Borneo, vol. 2, no. 1: Lycaenidae. Tobishima Corp, Tokyo

Simberloff DS (1978) Use of rarefaction and related methods in ecology. In: Dickson KL, Cairns J Jr, Livingston RJ (eds) Biological Data in Water Pollution Assessment: Quantitative and Statistical Analyses. American Society for Testing and Materials STP 652, Philadelphia, pp 150-165

StatSoft (2001) Statistica 6.0. Computer program and manual. StatSoft, Inc., Tulsa, OK (USA). http:// www.statsoft.com

Stearns SC (1992) The evolution of life histories. Oxford University Press, Oxford

Tangah J, Hill JK, Hamer KC, Dawood MM (2004) Vertical distribution of fruit-feeding butterflies in Sabah, Borneo. Sepilok Bull 1:15-25

Trueblood DD, Gallagher ED, Gould DM (1994) The three stages of seasonal succession on the Savin Hill Cove mudflat, Boston Harbor. Limnol Oceanogr 39:1440-1454

Wahlberg N, Braby MF, Brower AVZ, de Jong R, Lee M-M, Nylin S, Pierce NE, Sperling FAH, Vila R, Darren AD, Zakharov E (2005) Synergistic effects of combining morphological and molecular data in resolving the phylogeny of butterflies and skippers. Proc R Soc (B) 272: 1577-1586

Wendeln MC, Runkle LR, Kalko EKV (2000) Nutritional values of 14 fig species and bat feeding preferences in Panama. Biotropica 32:489-501

Wiens JJ, Graham CH (2005) Niche conservatism: Integrating evolution, ecology, and conservation biology. Annu Rev Ecol Evol Syst 36:519-539

Wiklund C, Gotthard K, Nylin S (2003) Mating system and the evolution of sex-specific mortality rates in two nymphalid butterflies. Proc R Soc (B) 270:1823-1828 